\title{
Relationship between Nonalcoholic Fatty Liver Disease and Vitamin D in Nepal
}

\author{
Manoj Kumar Sah, Ramila Shrestha, Bishnu Shrestha, Diwas Khadka
}

Bir Hospital, NAMS, Kathmandu, Nepal

\begin{abstract}
BACKGROUND AND AIMS

Vitamin D deficiency has been frequently reported in many causes of chronic liver disease and has been associated with the development and evolution of non-alcoholic fatty liver disease (NAFLD). The study was done to explore associations between serum vitamin D concentrations among obesity, diabetes mellitus, hypothyroidism, and metabolic syndrome and its effects on liver fibrosis by ultra-sonogram and $2 \mathrm{~d}$ shear wave elastography in patients with nonalcoholic fatty liver disease (NAFLD).
\end{abstract}

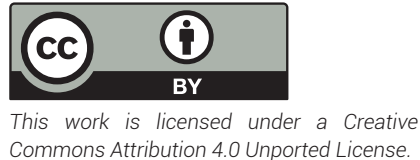

\section{METHODS}

A hospital based prospective observational study was conducted from May 2019 for twelve months period in Gastroenterology Unit, NAMS, Nepal. Seventy patients with known fatty liver identified by Ultrasonogram criteria were enrolled. All patients were evaluated by different fibrosis scores (NAFLD Fibrosis, FIB4, APRI, AST/ALT ratio) and 2d shear wave score. Patients were evaluated for Vitamin D level and its effects on obesity, diabetes mellitus, thyroid related disease, dyslipidemias and NAFLD.

\section{RESULTS}

Among 70 patients, 39 (55.7\%) were male and 31 (44.3\%) were female with mean age of 44.3 years. Most of the patients were overweight with mean BMI of $28.2 \mathrm{~kg} / \mathrm{m}^{2}$; among them $51(72.9 \%)$ were more than $25 . \mathrm{kg} / \mathrm{m}^{2}$. About $41.4 \%$ had diabetes mellitus, $77.1 \%$ had hypertension, 30\% had hypothyroidism and $25.9 \%$ had metabolic syndrome. Majority of patients on ultrasound grading were mild with $64.28 \% ; 25.72 \%$ were moderate and only $10 \%$ were in severe groups. A study of $2 \mathrm{~d}$ shear wave elastography showed mean fibrosis of $7.07 \mathrm{kpa}$ for mild grade, $8.22 \mathrm{kpa}$ for moderate grade and $18.16 \mathrm{kpa}$ for severe grade. The mean value of vitamin D was $22.61 \mathrm{iu} / \mathrm{ml}$ for mild grade, $24.89 \mathrm{iu} / \mathrm{ml}$ for moderate grade and $17.4 \mathrm{iu} / \mathrm{ml}$ for severe grade.

\section{CONCLUSION}

The results of this study showed high prevalence of serum $25(\mathrm{OH})$ vitamin D inadequacy in individuals with obesity, diabetes mellitus, hypothyroidism and metabolic syndrome which worsens as the stage of liver disease progresses.

\section{INTRODUCTION}

Vitamin D insufficiency and deficiency are prevalent in almost half the healthy population of developed countries?' Most experts define vitamin D insufficiency as a $25(\mathrm{OH})$ $\mathrm{D}$ level below $30 \mathrm{ng} / \mathrm{mL}$ and deficiency as levels below 20 $\mathrm{ng} / \mathrm{mL}$. It is estimated that one billion people suffer from deficiency or insufficiency of vitamin $D^{2}$

The outcome of vitamin D deficiency in terms of osteoporosis, osteomalacia and increased fracture risk is well known ${ }^{3,4}$. Furthermore, the association between vitamin $\mathrm{D}$ deficiency and the development of infections, cardiovascular, autoimmune and degenerative diseases and several types of cancer (colon, prostate and breast cancer) has also been reported ${ }^{5}$. Vitamin $D$ deficiency is extremely common in chronic liver disease patients. Up to $93 \%$ of these patients have some degree of vitamin insufficiency ${ }^{6,7}$. Several studies in general populations have shown that low levels of 25(OH)D significantly increase the risk of mortality from all causes, including cardiovascular diseases $^{8}$. Regarding patients with chronic liver disease of varying etiologies, vitamin $\mathrm{D}$ deficiency has been associated with increased mortality 9,10, bacterial infections, portal hypertension complications ${ }^{11}$ and fibrosis severity ${ }^{12}$.

NAFLD is the most common form of liver disease and a leading cause of morbidity and mortality in both developed and developing countries. ${ }^{13}$ NAFLD progresses to liver fibrosis and ultimately cirrhosis and its complication.

*Corresponding Author | Dr Manoj Kumar Sah,

Department of Medicine, Bir Hospital, NAMS, Kathmandu, Nepal

Email: najmanas10@gmail.com 
So early diagnosis and timely treatment with vitamin D is important to prevent cirrhosis related complications, mortality and healthcare cost.

Table : 1

\begin{tabular}{|l|c|}
\hline \multicolumn{1}{|c|}{ Base line Characteristics } & Total $(\mathrm{n}=70)$ \\
\hline Male & $39(55.7 \%)$ \\
\hline Female & $31(44.3 \%)$ \\
\hline Age & $44.3 \pm 12.1$ \\
\hline HDL. & $45 \pm 12.3$ \\
\hline LDL & $96 . \pm 35.2$ \\
\hline TG & $213.3 \pm 146$ \\
\hline AST & $64.5 \pm 117.1$ \\
\hline ALT & $63.3 \pm 80.3$ \\
\hline GGT & $70 \pm 75$ \\
\hline Platelets & $231.4 \pm 91.5$ \\
\hline AST/ALT ratio & $32(45.7 \%)$ \\
\hline Serum vitamin D mean level & $23.02 \pm 17.24$ \\
\hline
\end{tabular}

\section{METHODS}

The study was conducted from May 2019 for twelve months period in the Gastroenterology, NAMS, Nepal. The study was designed as a hospital based prospective observational study. Seventy patients with fatty liver in ultrasonography were enrolled in the study. The criteria of inclusion consisted of no consumption of alcoholic beverages for more than $20 \mathrm{~g} /$ day for women and $30 \mathrm{~g} /$ day for men, no chronic use of hepatotoxic medication, and negative HBsAG and HCV antibody tests. Complete general and systemic examination including anthropometry was done. Routine blood investigations were done.

Fatty liver and its severity was assessed by ultrasonography (USG) and 2d Shear wave elastography. Mean values of vitamin $D$ compared with grading of fatty liver and its severity by $2 d$ shear wave elastography. Grading of obesity assessed by body mass index (BMI) which measured by weight divided by height meter2 and its severity assessed by mean value of serum vitamin $D$ level. The effect of other metabolic diseases such as Diabetes mellitus (DM), Hypertension, Hypothyroidism, Dyslipidemia and Metabolic syndrome assessed with mean value of serum vitamin D level.

\section{RESULTS}

Among seventy patients 39(55.7\%) were male and 31(44.3\%) were female with mean age of the patients were 44.3. Most of the patients were overweight with mean BMI of 28.2, kg/ m2among them 51 (72.9\%) patients were more than $25 . \mathrm{kg} /$ m2Most of the patients $41.4 \%$ were diabetes mellitus, $77.1 \%$ were hypertension, $30 \%$ were hypothyroidism and metabolic syndrome were $25.9 \%$ as defined by Adult Treatment Panel III clinical definition of Mets. Other variables are given in Table 1.
In the quantitative ultrasound classification system devised by Saadeh et al., steatosis can be categorized as follows : grade 1 (mild)-mild, diffuse increase in hepatic echogenicity, the hepatic vessels and diaphragm having a normal aspect; grade 2 (moderate)-moderate, diffuse increase in hepatic echogenicity, the hepatic vessels and diaphragm having a blurred aspect; grade 3 (marked)marked increase in hepatic echogenicity, the hepatic vessels, diaphragm, and posterior liver not being visible. ${ }^{14}$ Among 70 patients majority of patients were mild 64.28\%, $25.72 \%$ were moderate and only $10 \%$ were in severe groups.

Table: 2 Mean Vitamin D level among BMI grade:

\begin{tabular}{|l|l|l|}
\hline WHO Grade & \multicolumn{1}{|c|}{ BMI } & Mean Serum vitamin Dlevel \\
\hline Normalrange & $18.5-24.9 \mathrm{~kg} / \mathrm{m} 2$ & $24.98 \pm 29.6$ \\
\hline Overweight & $25-29.9 \mathrm{~kg} / \mathrm{m} 2$ & $23.39 \pm 25.74$ \\
\hline Obesegrade1 & $30-34.9 \mathrm{~kg} / \mathrm{m} 2$ & $26.11 \pm 27.93$ \\
\hline Obesegrade2 & $35-39.9 \mathrm{~kg} / \mathrm{m} 2$ & $16.63 \pm 16.3$ \\
\hline Obesegrade3 & $->40 \mathrm{~kg} / \mathrm{m} 2$ & 9.35 \\
\hline
\end{tabular}

Table: 3 Vitamin D level on severity of liver diseases:

\begin{tabular}{|l|l|l|l|}
\hline $\begin{array}{l}\text { Gradingfibrosis } \\
\text { of liver disease }\end{array}$ & $\begin{array}{l}\text { USGgrading } \\
\text { of fatty liver }\end{array}$ & $\begin{array}{c}\text { 2D Shear wave } \\
\text { Elastography } \\
\text { mean value }\end{array}$ & $\begin{array}{c}\text { Serum } \\
\text { vitamin D } \\
\text { level }\end{array}$ \\
\hline Mild & Grade 1 & 7.07 & $22.61 \pm 28.07$ \\
\hline Moderate & Grade 2 & 8.22 & $24.89 \pm 26.45$ \\
\hline Severe & Grade 3 & 18.16 & $17.4 \pm 6.4$ \\
\hline
\end{tabular}

Table: 4 Vitamin D level on other metabolic diseases:

\begin{tabular}{|l|l|l|}
\hline \multicolumn{1}{|c|}{ Metabolic diseases } & $\begin{array}{c}\text { Totalnumberof } \\
\text { patients }\end{array}$ & $\begin{array}{c}\text { Mean vitamin D } \\
\text { level }\end{array}$ \\
\hline NAFLD & $70(100 \%)$ & $23.02 \pm 28.07$ \\
\hline BMI >25 & $51(72.9 \%)$ & $19.10 \pm 25.74$ \\
\hline Diabetes mellitus & $29(41.4 \%)$ & $25.27 \pm 26.45$ \\
\hline Hypertension & $54(77.1 \%)$ & $31.68 \pm 28.07$ \\
\hline Hypothyroidism & $21(30 \%)$ & $18.29 \pm 17.52$ \\
\hline Metabolic Syndrome & $18(25.9 \%)$ & $22.65 \pm 26.45$ \\
\hline Dyslipidemia & $17(24.28 \%)$ & $24.01 \pm 29.95$ \\
\hline
\end{tabular}

\section{DISCUSSION}

Low vitamin $\mathrm{D}$ is prevalent in chronic liver disease patients. Even patients with mild liver disease are affected, although patients with liver cirrhosis are more commonly have severe deficiency?. Low serum levels of vitamin D have been observed in chronic liver diseases, especially with liver 
cirrhosis $^{15}$, while in patients with NAFLD, the data are still scanty in Nepal. Our study demonstrates that the serum 25 $(\mathrm{OH}) \mathrm{D}$ was significantly lower in the NAFLD was evaluated by $2 \mathrm{~d}$ shear wave elastography. ${ }^{16}$ More than two thirds of NAFLD patients had vitamin D deficiency.

A systematic review of Pacifico and colleagues ${ }^{17 i n c l u d e d}$ 45 studies exploring the association between vitamin D status and NAFLD/NASH. Of them, 29 studies reported an inverse association between vitamin D status and NAFLD, while 16 studies did not support this association. On the other hand, the meta-analysis on the relationship between serum vitamin D and NAFLD histologic severity found no association between serum vitamin $D$ levels and disease severity as assessed by NAS and fibrosis score among patients with NAFLD ${ }^{18}$.

In our study, the individuals with higher BMI and body weight were those who suffered NAFLD, and further studies highlight how there is a strong association between excessive adiposity and NAFLD. This association causes predisposition to systemic hypertension, dyslipidemia, and inflammation. Although Vitamin D deficiency (VDD) mechanisms that contribute to the deposition of fat in the liver are not yet well understood, studies show that VDD may be involved in the regulation of insulin action and could relate to a decrease in secretion of this hormone ${ }^{19}$, Vitamin D also modulates the metabolism of free fatty acids (FFAs) acting on peroxisome proliferator-activated receptor (PPAR-), thereby relieving FFA-induced insulin resistance in vitro. Consequently the increased FFAs flowing in the bloodstream could promote fat deposition into the hepatocytes and the progression of NAFLD on condition of vDD20.

\section{CONCLUSION}

The results of this study showed high prevalence of serum $25(\mathrm{OH})$ vitamin D inadequacy in individuals with obesity, diabetes mellitus, hypothyroidism and metabolic syndrome which worsens as the stage of liver disease progresses.

\section{REFERENCES}

1. Holick MF. Vitamin D deficiency. N Engl J Med 2007; 357: 266281 [PMID: 17634462]

2. Holick MF. Vitamin D: evolutionary, physiological and health perspectives. Curr Drug

Targets 2011; 12: 4-18 [PMID: 20795941].

3. Pérez-López FR. Vitamin $D$ and its implications for musculoskeletal health in women: an update. Maturitas 2007; 58: 117-137 [PMID: 17604580]

4. Looker AC, Mussolino ME. Serum 25-hydroxyvitamin D and hip fracture risk in older U.S. white adults. J Bone Miner Res 2008; 23: 143-150 [PMID: 17907920]
5. Peterlik M, Cross HS. Vitamin D and calcium deficits predispose for multiple chronic diseases. Eur J Clin Invest 2005; 35: 290304 [PMID: 15860041]

6. Fisher L, Fisher A. Vitamin D and parathyroid hormone in outpatients with noncholestatic chronic liver disease. Clin Gastroenterol Hepatol 2007; 5: 513-520 [PMID: 17222588]

7. Arteh J, Narra S, Nair S. Prevalence of vitamin D deficiency in chronic liver disease. Dig Dis Sci 2010; 55: 2624-2628 [PMID: 19960254 DOI: 10.1007/s10620-009-1069-9

8. Pilz S, Tomaschitz A, März Wet al. Vitamin D, cardiovascular disease and mortality. Clin Endocrinol (Oxf) 2011; 75: 575-584 [PMID: 21682758 DOI: 10.1111/j.1365-2265.2011]

9. Trépo E, Ouziel R, Pradat P, Momozawa $Y$ et al Marked 25-hydroxyvitamin $D$ deficiency is associated with poor prognosis in patients with alcoholic liverdisease. J Hepatol 2013; 59: 344-350 [PMID: 23557869 DOI: 10.1016/j. jhep.2013.03.024]

10. Putz-Bankuti C, Pilz S, Stojakovic T, et al. Association of 25-hydroxyvitamin D levels with liver dysfunction and mortality in chronic liver disease. Liver Int 2012; 32: 845851 [PMID: 22222013 DOI: 10.1111/j.1478-3231.2011.02735.x]

11. Anty R, Tonohouan M, Ferrari-Panaia P et al Low Levels of 25-Hydroxy Vitamin D are independently Associated with the Risk of Bacterial Infection in Cirrhotic Patients. Clin Transl Gastroenterol 2014; 5: e56 [PMID: 24871371 DOI 10.1038/ ctg.2014.6]

12. Targher G, Bertolini L, Scala L, et. al Associations between serum 25-hydroxyvitamin D3 concentrations and liver histology in patients with non-alcoholic fatty liver disease. Nutr Metab Cardiovasc Dis 2007; 17: 517-524 [PMID: 16928437]

13. Younossi Z, Anstee Q.M, Marietti $M$ et al. Global burden of NAFLD and NASH: Trends, predictions, risk factors and prevention. Nat. Rev. Gastroenterol. Hepatol. 2018;15:11-20.

14. Saadeh S, Younossi ZM, Remer EM, et al. The utility of radiological imaging in nonalcoholic fatty liver disease. Gastroenterology. 2002; 123:745-50.

15. Kitson MT, Roberts SK (2012) D-livering the message: the importance of vitamin D status in chronic liver disease. J Hepatol 57:897-909

16. Sah M K, Basnet B K: Noninvasive assessment of liver fibrosis in Nonalcoholic Fatty Liver Disease in Nepal JAIM Vol 9 No 1;2020: 25-28

17. Pacifico L, Osborn JF, Bonci E, Pierimarc hi P, Chiesa C (2019) Association between vitamin $\mathrm{D}$ levels and nonalcoholic fatty liver disease: potential confounding variables. Mini-Reviews Med Chem 19:310-332

18. Jaruvongvanich V, Ahuja W, Sanguankeo A, Wijarnpreecha K, Upala S (2017) Vitamin D and histologic severity of nonalcoholic fatty liver disease: a systematic review and meta-analysis. Dig Liver Dis 49:618-622

19. J. A. Alvarez and A. Ashraf, "Role of vitamin D in insulin secretion and insulin sensitivity for glucose homeostasis," International 
Journal of Endocrinology, vol. 2010, Article ID 351385, 18 pages, 2010.

20. I. Barchetta, F. Angelico, M. D. Ben et al., "Strong association between non alcoholic fatty liver disease (NAFLD) and low $25(\mathrm{OH})$ vitamin $\mathrm{D}$ levels in an adult population with normal serum liver enzymes," BMC Medicine, vol. 9, article 85, 2011. 